\title{
Academic Achievements in National Competence Assessment Among Health Extension Students in Regional Health Science Colleges, Amhara Region, Ethiopia
}

This article was published in the following Dove Press journal:

Advances in Medical Education and Practice

\author{
Ayesheshim Muluneh Kassa' \\ Getahun Gebre Bogale (D) ${ }^{2}$ \\ 'Department of Nursing, Dessie Health \\ Science College, Dessie, Ethiopia; \\ ${ }^{2}$ Department of Health Informatics, \\ School of Public Health, College of \\ Medicine and Health Sciences, Wollo \\ University, Dessie, Ethiopia
}

Background: The national competency assessment (NCA) is a strategy with the objective of creating a competent, motivated, adaptable and innovative workforce in Ethiopia. However, of all the students that had taken the NCA, below average students had passed the assessment in the study settings. Therefore, this study aimed to assess the level of academic achievements of health extension students (HESs) and identify the influencing factors that contribute to the failure of HESs on NCA in the study settings.

Methods: An institution-based cross-sectional study complemented with qualitative methods was conducted from 18th to 27th January 2019 of a sample of 186 level III health extension students in Regional Health Science Colleges. A self-administered structured questionnaire and focus group discussion guiding tool were used to collect the data. The data were checked for completeness, coded and entered into EPI info version 7.1.0 and exported to SPSS version 20 for analysis. Bivariate logistic regression analysis was done to assess the association between each independent variable and the outcome variable with $\mathrm{p}<0.25$. Multivariable analysis was done to control the influence of potential confounding variables and to identify influencing factors. The significant level was declared at $\mathrm{p}<0.05$.

Results: A total of 186 study subjects were involved in the study with a response rate of $100 \%$. Of the total participants, only $31.7 \%$ of students passed the national competency assessment. After adjusting for covariates, fathers' education level, fathers' occupation, and students' English language understanding were significantly associated with the passing of the NCA.

Conclusion: Students' competency in the NCA is below average. Therefore, the health science colleges should give due attention to the inclusion of the English language as a unit of competency. The regional government and stakeholders should give priority to paternal awareness about the health extension program. Follow-up studies are recommended exploring other influencing factors related to the NCA.

Keywords: HESs, NCA, DHSC, Ethiopia

\section{Introduction}

Education is the cornerstone for the nation's economic, cultural, scientific, and social development. ${ }^{1,2}$ Furthermore, both private and public universities, colleges and schools have a greater role in the production of an educated society. ${ }^{3}$ In Ethiopia, the Regional Health Science Colleges have been playing a role in producing mid-level and high-level professionals since before the expansion of governmental universities and private colleges. ${ }^{4,5}$

Ayesheshim Muluneh Kassa

Department of Nursing, Dessie Health

Science College, P.O. Box 1212, Dessie,

Ethiopia

Tel +25I 9I I 199645

Email ashumuluneh327@gmail.com 
The Health Extension Program (HEP) was launched by the Federal Ministry of Health (FMoH) in 2003. Its goal is to improve health outcomes in Ethiopia by targeting households and communities. ${ }^{6}$ Moreover, the HEP incorporates a package of basic and essential promotive, preventive, and curative health services according to the principles of primary health care to improve family health status with the active participation of both households and the community. ${ }^{7,8}$

The national Technical and Vocational Education and Training (TVET) strategy was developed and replaces an older version adopted in 2002. The strategy, with the objective of creating a competent, motivated, adaptable and innovative workforce in Ethiopia, is contributing a lot to poverty reduction and social and economic development by facilitating demand-driven, high quality technical and vocational education and training, relevant to all sectors of the economy, at all levels and to all people. Following this, there is considerable expansion in TVET institutions in Ethiopia, both in terms of public spending and increased provision by private institutions. ${ }^{9,10}$

The students' academic performance plays a vital role in creating qualified manpower for the country that is responsible for the country's economic and social development. Student's academic performance is affected by the assessment tool, psychological, socioeconomic, personal and environmental factors. ${ }^{1,11,12}$ Though there is a scarcity of information regarding students results in the national competency assessment (NCA), unpublished reports of five consecutive academic years in Dessie Health Science College (DHSC) showed that less than half (with a range of $24 \%$ to $41.37 \%$ ) the students who took this competency assessment passed (DHSC, 2014-18, Annual academic performance reports, unpublished). Reports from the rest of the four Regional Health Science Colleges (RHSCs) showed similar phenomena.

However, studies are limited to the status of and associated factors of the quality of the NCA in developing nations, including Ethiopia. This study identified the gaps regarding the incompetency of health extension students (HESs) in the Amhara region. Therefore, this study was aimed to assess the level of academic achievements of the NCA and its influencing factors among the HESs of RHSCs in Amhara national regional state (ANRS), Ethiopia.

\section{Methods}

\section{Study Setting}

There are about twenty-three RHSCs in Ethiopia. The five of them are Dessie, Bahir Dar, Debre Birhan, Teda, and Debre
Tabor RHSCs found in ANRS, Ethiopia. All colleges have been enrolling level III health extension students since 2004. The colleges are public academic institutions and are using harmonized curricula. The selected RHSC is Dessie Health Science College (DHSC) which is located in Dessie City administration, ANRS, $401 \mathrm{~km}$ far away in the northeast of Addis Ababa (the capital city of Ethiopia). The College has been training different middle level and high level health professionals. It has been giving trainings in a multidisciplinary approach; namely; Comprehensive Nursing, Midwifery, Health Extension, Anesthesia, Emergency Medical Technician, Medical Laboratory, Pharmacy, Radiology and Health Information Technology.

\section{Study Design and Period}

An institution based cross-sectional study complemented with a qualitative study was conducted in RHSCs, ANRS, Ethiopia, from January 18 to 27, 2019.

\section{Population}

The reference population was all level III health extension students (2018/19 enrolled) who attended at the five RHSCs. The study population was all level III HESs (2018/19 enrolled) who attended DHSC.

\section{Sample Size Determination and Sampling Procedures}

The RHSCs are almost similar in capacity and even their students came from similar socio-cultural backgrounds. Due to such similarities, based on the experts' recommendation (just as a rule of thumb), one (20\%) of the five Colleges was selected using a simple random sampling method. That is the Dessie Health Science College. All 186 level III HESs of DHSC were included in the study (Figure 1).

\section{Data Collection Process}

For a quantitative study, a self-administered questionnaire was used to collect the data. The questionnaire was prepared in the English version and translated into the Amharic version and translated back to the English language. Data collectors were hired for this particular study to attain the quality of data. Six data collectors and three supervisors participated in the data collection process. Training with the objective of the study and how to fill the structured questionnaire during the data collection was given to data collectors and the supervisors for one day before the data collection. The investigators with two other 


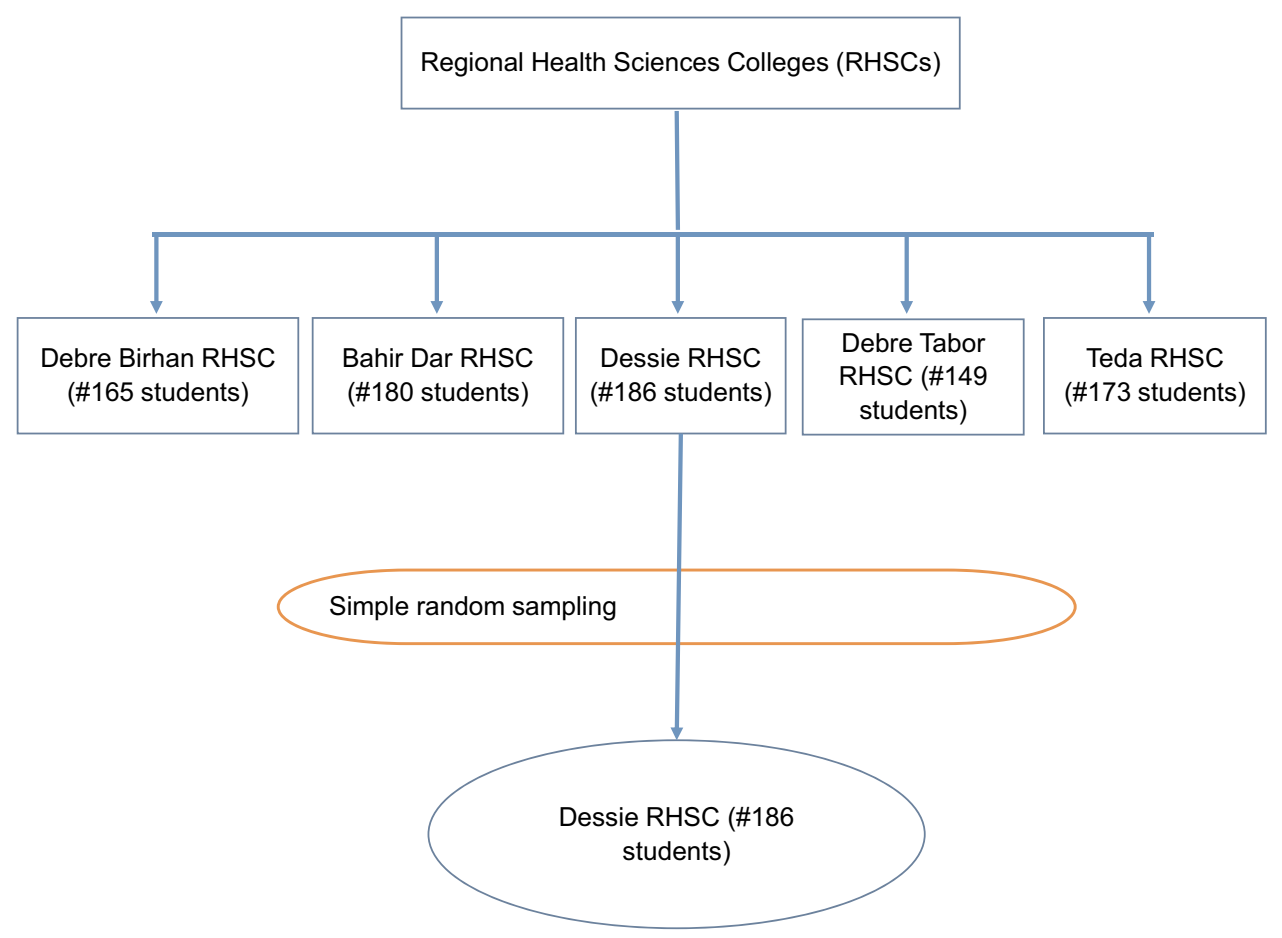

Figure I Schematic diagram for assessing the status of academic achievements and its influencing factors among HESs of DHSC, ANRS, Ethiopia.

supervisors supervised the data collection procedure. The filled questionnaires were checked for completeness by the investigators and/or the supervisors on a daily basis.

For the qualitative one, three focus group discussions (FGD) in each group, involving ten students, were conducted. Semi-structured guiding questions were prepared by referring to different qualitative related academic issues to lead the discussion. To have adequate data and information to reach saturation, note-taking and audio recording were employed during data collection.

\section{Operational Definitions}

National competency assessment (Ethiopia): Nationwide assessment, which is evidence-based information gathered to prove competency. The process may be applied to an employable single unit of competency, a cluster of relevant units of competency or all units of competency in a full national qualification.

Pass with NCA: a candidate who got 18 out of 36 with a knowledge test and showed satisfactory skill levels.

Fail with NCA: a candidate who got either under 18 out of 36 with the knowledge test and/or not satisfied with the skill levels shown.

\section{Data Management and Analysis}

For quantitative data, the data were checked for its completeness, coded and entered into EPI info version 7 and exported to SPSS version 20 for analysis. Descriptive and summary statistics were carried out. Binary logistic regression was performed to see the association of academic performance with socioeconomic characteristics, institutional factors and family related factors. Explanatory variables which had a significant association with academic performance at $p<0.25$ in the bivariate logistic regression were entered in a multivariable logistic regression model. Multivariable logistic regression was done to control confounding factors and to get a less biased estimation of the association between explanatory and outcome variables. Adjusted odds ratio (AOR) with $95 \%$ confidence intervals was estimated to assess the strength of the association, and the statistical significance level was declared at $p<0.05$.

Qualitative data were analyzed manually, which involved coding, examining, comparing and categorizing the data and writing the findings. Finally, qualitative data were presented by triangulating with quantitative findings. The information was presented in narrations using well-said word-by-word examples of the study participants as illustrations. 


\section{Results}

\section{Quantitative results}

Socio-Demographic Characteristics of Respondents

A total of 186 HESs were included in the study with a response rate of $100 \%$. Among the study subjects, 76 (40.9\%) were Orthodox Christian and 110 (59.1\%) were Muslim religion followers. Of the study subjects, 36 (19.4\%) were in the age group of 15-19 years and the rest $150(55.1 \%)$ were in the age group of 20-25 years and their mean $( \pm \mathrm{SD})$ age was $20.16( \pm 0.9)$ years. The majority of respondents, $184(98.9 \%)$ were Amhara in ethnicity, 167 (89.8\%) single, 179 (96.2\%) have no child, and 167 (89.8\%) from a father with the occupation of farmer (Table 1).

\section{National Competency Assessment-Related Variables}

Of the total participants; only 59 (31.7\%) students passed the national competence assessment (Figure 2).

On the basis of reasons for their failure; 17 (9.1\%) students reported that there are assessor related problems that can be considered as reason to fail and 88 (37.1\%) study participants explained the incompatibility between the national competence assessment and the given training as the main reason to fail in the NCA. However, more than half of the respondents (69.4\%) agreed upon the presence of NCA (Table 2).

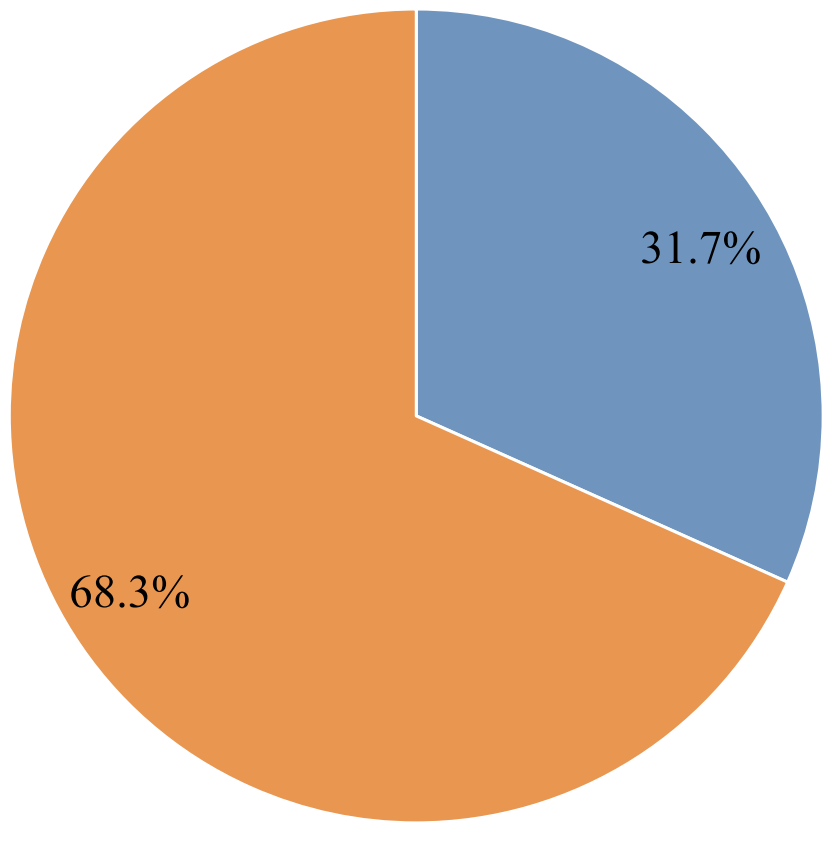

\section{- Pass NCA $\quad$ Fail NCA}

Figure 2 NCA result among HESs of DHSC, ANRS, Ethiopia.
Table I Socio-Demographic Characteristics of HESs of DHSC, ANRS, Ethiopia

\begin{tabular}{|c|c|c|}
\hline Demographic Characteristics & Frequency & Percentage \\
\hline \multicolumn{3}{|l|}{ Age group } \\
\hline $15-19$ & 36 & 19.4 \\
\hline $20-25$ & 150 & 80.6 \\
\hline \multicolumn{3}{|l|}{ Religion } \\
\hline Orthodox Christian & 76 & 40.9 \\
\hline Muslim & 110 & 59.1 \\
\hline \multicolumn{3}{|l|}{ Residence (precollege) } \\
\hline Urban & 41 & 22 \\
\hline Rural & 145 & 78 \\
\hline \multicolumn{3}{|l|}{ Marital status } \\
\hline Single & 167 & 89.8 \\
\hline Married & 14 & 7.5 \\
\hline Divorced and windowed & 5 & 2.6 \\
\hline \multicolumn{3}{|l|}{ Household head of the family } \\
\hline Father & 146 & 78.5 \\
\hline Mother & 29 & 15.6 \\
\hline Husband and relatives & II & 5.9 \\
\hline \multicolumn{3}{|l|}{ Father educational status } \\
\hline Not read and write & 56 & 30.1 \\
\hline Read and write & 90 & 48.4 \\
\hline Primary and above & 40 & 21.5 \\
\hline \multicolumn{3}{|l|}{ Mother educational status } \\
\hline Not read and write & 86 & 76.2 \\
\hline Read and write & 89 & 47.8 \\
\hline Primary and above & II & 5.8 \\
\hline \multicolumn{3}{|l|}{ Father occupation } \\
\hline Farmer & 167 & 89.8 \\
\hline Merchant & $\mathrm{II}$ & 5.9 \\
\hline Governmental employee & 8 & 4.3 \\
\hline \multicolumn{3}{|l|}{ Mother occupation } \\
\hline Farmer & 168 & 90.3 \\
\hline Merchant & II & 5.9 \\
\hline Governmental employee & 4 & 2.2 \\
\hline Housewife, NGO and daily laborer & 3 & 1.6 \\
\hline \multicolumn{3}{|l|}{ Family income in ETB } \\
\hline 1000 and below & 68 & 36.6 \\
\hline $1001-2000$ & 75 & 40.3 \\
\hline Above 2000 & 43 & 23.1 \\
\hline
\end{tabular}

\section{Professional Satisfaction and Educational Background-Related Variables}

Of the total participants; more than half (51.1\%) of the participants were not interested in their profession, and half $(50.5 \%)$ of the participants believed that the 
Table 2 NCA Result and Related Issues Among HESs of DHSC, ANRS, Ethiopia

\begin{tabular}{|l|l|l|}
\hline NCA-Related Variables & Frequency & Percentage \\
\hline Reasons for failure in NCA & 58 & \\
Fear of NCA & 27 & 45.7 \\
Knowledge gap & 17 & 21.3 \\
Skill gap to demonstrate & 49 & 13.4 \\
Computer skill gap & 17 & 38.6 \\
Assessor's related & 91 & 13.4 \\
Language barrier & 88 & 71.7 \\
Incompatible NCA with the given & & 69.3 \\
trainings & & \\
\hline Conditions needed to pass the NCA & & \\
Paying attention for class & 108 & 58.1 \\
Hard reading & 90 & 48.4 \\
Getting tutors & 97 & 41.4 \\
Re-demonstration & 108 & 50 \\
Study in groups & & 58 \\
\hline Confidence in NCA & 73 & \\
Very confident & 90 & 39.2 \\
Confident & 19 & 48.4 \\
Not confident & 3 & 10.2 \\
Not very confident & 57 & 1.6 \\
\hline Support presence of NCA & & \\
Yes & & \\
No & & 3.4 \\
\hline Reasons not to support presence of & & \\
NCA & & \\
Not measurable exam & & \\
Bias & & \\
Incompatible NCA with the given & 6.4 \\
\hline
\end{tabular}

community was not respected for their profession. Of the total participants; only (15.1\%) of respondents never practiced in a re-demonstration beyond their observation during the session. The majority of students $(91.9 \%)$ did not get any academic advice from their respective advisors. About $73.1 \%$ and $87.1 \%$ of participants never knew about the presence of a tutorial class and had never attended tutorial classes respectively (Table 3 )

\section{Factors Associated with National Competency Assessment}

To evaluate the association between each exposure variable and the dependent variable, a bivariate logistic regression analysis was done with OR and $95 \%$ CI. In the bivariate analysis; students' parental education and occupation, students' own income level and students' ability in the English language were found to be potential candidate variables for the second regression model.

In the multivariable logistic regression analysis; students' parental education and occupation and students' ability in the English language were significantly associated with the academic achievement of NCA. The odds of passing the NCA among students whose fathers can read and write was 3.2 times higher compared to those whose fathers cannot read and write $(\mathrm{AOR}=3.17,95 \%$ CI: 1.33, 7.62). Moreover, the odds of passing the NCA among students whose fathers attended primary school were 3 times higher compared to those whose fathers did not attend primary school $(\mathrm{AOR}=2.91,95 \% \mathrm{CI}$ : $1.02,8.32)$.

Students with merchant fathers were 7 times more likely to pass the NCA as compared to those whose fathers were farmers $(\mathrm{AOR}=6.99,95 \% \mathrm{CI}: 1.41,34.55)$. The likelihood of passing the exam among students who could understand lessons with the English language were 7.5 fold more reported as compared to those who could not understand ( $\mathrm{AOR}=7.54,95 \% \mathrm{CI}: 2.99,19.56)$ (Table 4).

\section{Qualitative Results}

Three FGD groups, each involving ten students, discussed the importance of the NCA and its impact on the students' knowledge, attitude and practice towards the NCA performances and further in the workplace later on.

The 21 year-old-student said that " ... I think it is important. If there is no NCA, we cannot attend the class . . . "... "the reasons why we failed in the national competency assessment are lack of training in skill gaps and institutional model exam at the college level that may capacitate our ability to pass the national exam ..." . Another 23-year-old health extension student explained that;

... even if there are some differences in the composition of the assessment, it is important. Because this may initiate the students' careful preparation mostly for the practical exam, but the assessment technique should be balanced for all candidates ....

The majority of students concluded that the national competency assessment is necessary. However, they complained about the assessment delivery system. They extremely disliked the computer-based examination as one explained; 
Table 3 Satisfaction-Related Characteristics Among HESs of DHSC, ANRS, Ethiopia

\begin{tabular}{|c|c|c|}
\hline Variables & Frequency & Percentage \\
\hline \multicolumn{3}{|l|}{$\begin{array}{l}\text { Interest in Health Extension } \\
\text { profession }\end{array}$} \\
\hline Very interested & 30 & 16.1 \\
\hline Interested & 61 & 32.8 \\
\hline Not interested & 79 & 42.5 \\
\hline Not very interested & 16 & 8.6 \\
\hline \multicolumn{3}{|l|}{ Reasons for being uninterested } \\
\hline Dissatisfaction with the profession & 14 & 7.5 \\
\hline Low salary & 32 & 17.2 \\
\hline The profession is not family favourite & 26 & 14 \\
\hline $\begin{array}{l}\text { Community not respect the } \\
\text { profession }\end{array}$ & 94 & 50.5 \\
\hline Less chance of upgrading & 89 & 47.8 \\
\hline The profession is tedious & 59 & 31.7 \\
\hline \multicolumn{3}{|l|}{ Grade 10 EGSLCE* result } \\
\hline $2.00-2.28$ & 91 & 48.9 \\
\hline $2.43-2.57$ & 77 & 41.4 \\
\hline$\geq 2.71$ & 18 & 9.7 \\
\hline \multicolumn{3}{|l|}{ Grade 12 ESLCE** result } \\
\hline Took Grade 12 ESLCE & 53 & 28.5 \\
\hline$<300$ & 19 & 35.8 \\
\hline$\geq 300$ & 34 & 64.2 \\
\hline \multicolumn{3}{|l|}{ English language understanding ability } \\
\hline Understand well & 5 & 2.7 \\
\hline Understand & 113 & 60.8 \\
\hline Difficult to understand & 56 & 30.1 \\
\hline Cannot understand & 12 & 6.5 \\
\hline \multicolumn{3}{|l|}{ Study hour per day } \\
\hline 30 minutes -2 hours & 84 & 45.2 \\
\hline $3-5$ hours & 95 & 51.1 \\
\hline 6 hours and above & 7 & 3.8 \\
\hline \multicolumn{3}{|l|}{ Re-demonstration hour per day } \\
\hline Never re-demonstrate & 15 & 8.1 \\
\hline 30 minutes- 2 hours & 156 & 83.8 \\
\hline 3 hours and above & 15 & 8 \\
\hline \multicolumn{3}{|l|}{ Knowing the presence of advisor } \\
\hline Yes & 61 & 32.8 \\
\hline No & 125 & 67.2 \\
\hline \multicolumn{3}{|l|}{ Academic advice from the advisors } \\
\hline Yes & 15 & 8.1 \\
\hline No & 171 & 91.9 \\
\hline \multicolumn{3}{|l|}{$\begin{array}{l}\text { College rule and regulation had } \\
\text { negative influence on academic } \\
\text { performance }\end{array}$} \\
\hline Yes & 15 & 8.1 \\
\hline
\end{tabular}

(Continued)
Table 3 (Continued)

\begin{tabular}{|l|l|l|}
\hline Variables & Frequency & Percentage \\
\hline No & 171 & 91.9 \\
\hline $\begin{array}{l}\text { Negative impact of peer pressure on } \\
\text { academic performance } \\
\text { Yes }\end{array}$ & 17 & 9.1 \\
No & 169 & 90.9 \\
\hline $\begin{array}{l}\text { Know presence of tutorial class } \\
\text { Yes }\end{array}$ & 50 & 26.9 \\
No & 136 & 73.1 \\
\hline Attended tutorial class & & \\
Yes & 24 & 12.9 \\
No & 162 & 87.1 \\
\hline
\end{tabular}

Notes: *Ethiopian General Secondary Leaving Certificate Examination. **Ethiopian Secondary Leaving Certificate Examination.

... it is not fair and balance for all students; for some bodies it may be easy, and for most of us it is very hard to do. Because most of us are not familiar with the new system and even with computer manipulation.

A 20-year-old student said that;

... theoretical assessment by computer is so difficult, especially; in the matching part all the possible alternatives in the column ' $\mathrm{B}$ ' should be visible. We also complain about the handling of the assessors who are making frighten, shortening the given time and harsh type of insulting.

Another 19 years old said " ... for most of us, understanding the English language is difficult, so the college should prepare the tutorial class for us".

On the other hand, the groups raised synergistic perceived frustrations at their work post-education. They explained as “... being a health extension worker is very tiresome, marginalized work, everybody is not respecting our profession." They said “ ... we are not interested in our profession. As per the experiences of our friends who have been assigned in the working area, we will be working loaded with other government activities like leading farmers development army and one to five groups, collection of the loan, agricultural activities, arbitration, and so on, ... and the communities disrespect

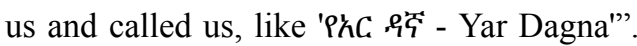

A twenty-two-year old student said that; 
Table 4 Factors Associated with the Status of NCA Result Among HESs of DHSC, ANRS, Ethiopia

\begin{tabular}{|c|c|c|c|c|}
\hline \multirow[t]{2}{*}{ Variables } & \multicolumn{2}{|c|}{ Status of NCA } & \multirow[t]{2}{*}{ Crude OR $(95 \% \mathrm{Cl})$} & \multirow[t]{2}{*}{ AOR $(95 \% \mathrm{Cl})$} \\
\hline & Pass & Fail & & \\
\hline \multicolumn{5}{|l|}{ Father education } \\
\hline Cannot read and write & $10(5.4 \%)$ & 46 (24.7\%) & 1 & I \\
\hline Read and write & $33(17.7 \%)$ & 57 (30.6\%) & $2.66(1.19,6.0)^{*}$ & $3.19(1.33,7.62)^{* *}$ \\
\hline Primary and above & $16(8.6 \%)$ & 24 (12.9\%) & $3.07(1.21,7.79)^{*}$ & $2.91(1.02,8.32)^{*}$ \\
\hline \multicolumn{5}{|l|}{ Mother education } \\
\hline Cannot read and write & $21(11.3 \%)$ & 65 (34.9\%) & 1 & I \\
\hline Read and write & $35(18.8 \%)$ & $54(29 \%)$ & $2.01(1.05,3.84)^{*}$ & $1.38(0.58,3.27)$ \\
\hline Primary and above & $3(1.6 \%)$ & $8(4.3 \%)$ & $1.16(0.28,4.78)$ & $0.53(0.08,3.40)$ \\
\hline \multicolumn{5}{|l|}{ Father occupation } \\
\hline Farmer & $50(26.9 \%)$ & 117 (63\%) & I & I \\
\hline Merchant & $8(4.3 \%)$ & $3(1.6 \%)$ & $6.24(1.59,24.5)^{* *}$ & $7.0(1.4 I, 34.55)^{*}$ \\
\hline Government employee & I (0.5\%) & 7 (3.8\%) & $0.33(0.04,2.80)$ & $0.20(0.02,1.87)$ \\
\hline \multicolumn{5}{|l|}{ Mother occupation } \\
\hline Farmer & $49(26.3 \%)$ & $119(64 \%)$ & I & I \\
\hline Others $^{+}$ & $10(5.4 \%)$ & $8(4.3 \%)$ & $3.04(1.11,8.15)^{*}$ & $3.27(0.25,42.39)$ \\
\hline \multicolumn{5}{|l|}{ Own income } \\
\hline $0-500$ & $33(17.7 \%)$ & $82(44.1 \%)$ & I & I \\
\hline $50 I-750$ & $12(6.5 \%)$ & $31(16.7 \%)$ & $0.96(0.44,2.10)$ & $0.86(0.35,2.08)$ \\
\hline$>750$ & 14 (7.5\%) & $14(7.5 \%)$ & $2.49(1.10,5.78)^{*}$ & $3.53(0.96,12.95)$ \\
\hline \multicolumn{5}{|l|}{ English language ability } \\
\hline Understand & $52(28 \%)$ & 66 (35.5\%) & $6.87(2.90,16.27)^{* *}$ & $7.55(3.00,19.57)^{* *}$ \\
\hline Not Understand & 7 (3.8\%) & $6 \mathrm{I}(32.8 \%)$ & 1 & I \\
\hline
\end{tabular}

Notes: ${ }^{*} p<0.05,{ }^{*} p<0.01$, ${ }^{+}$house wife, Government employee and Merchant, NGO and daily laborer.

... mostly fresh teachers were assigned to us and had a lack of knowledge and skill in some area of subjects, especially subjects that need practice. Some instructors underestimate us as we don't know anything, and they come to class without any preparations.

\section{Discussion}

This study revealed that only $31.7 \%$ (95\% CI: $25.4 \%$, $36.3 \%$ ) of students passed the national competency assessment. The students' father's education status and occupation, and students' English language understanding ability were significantly associated with their academic achievements in the NCA.

The health extension students' academic achievement, surprisingly, was too small and incomparable with other students' academic performances in the study settings. It is lower than a study done at Debre Birhan Health Science College, Ethiopia. ${ }^{13}$ The difference might be due to dissimilarities between study subjects across departments. That means this study considered only health extension students (who are all females), however, the comparable one included all departments irrespective of their sex. Even though comparable studies are lacking in similar study subjects, as our professional's suggest, students' language barrier and low academic background might contribute to this low academic performance. The Ethiopian Ministry of Education/TVET Agency in collaboration with the Ministry of Health may need to revise the media of instruction and admission criteria.

The result of this study showed that students from educated families (particularly fathers) were more likely to pass the NCA than those who came from uneducated families. The more their families were educated, the better the students' academic performance was reported. This finding is supported by studies focusing on factors affecting female students' academic performance in higher education done in Bahir Dar University, Ethiopia and Private Colleges of Bangladesh. ${ }^{14,15}$ The possible reasons could be that fathers who are educated can support their daughters' efforts in the learning-teaching process, starting from 
primary school to higher education in academic issues and other aspects which need an easy understanding of the education environment. It is important to consider "basic education for all citizens" as it might play as a key factor for all types of events.

Students who came from merchant families were more successful with their academic performance than those who came from farming families. This result is consistent with the finding of a study done in Bahir Dar University, Ethiopia that showed family income has its own impact on students' academic performance. ${ }^{15}$ It could be due to the differences in family income which might impact on variations of parents' occupation. Also, the level of awareness between merchant and farmer parents towards education in supporting their daughters may lead to this variation. So, it is important to increase parents' wage at the community level through region-wide development.

Students who had an ability to understand the English language as a medium of instruction had better academic achievements as compared to those who had less language skill. This is supported by ideas expressed in the FGD sessions. Similar to this finding, a study done in Nigeria showed that competence in the required English language was determining the students' academic performance. ${ }^{16,17}$ It is also supported by another study done at the Be nadir University, Malaysia which found that communication skill was among the identified factors that promote academic performance. ${ }^{18}$ It is clear that the English language is the medium of instruction for higher education trainings. It is also in line with the studies done in the United States ${ }^{19}$ and Saudi Arabia, ${ }^{20}$ in which students who had reported high levels of self-perceived English language proficiency had high levels of performance. So, those who have good English language understanding can understand points being discussed by the teacher in class and read and understand what is written in different lecture notes and references. Also communication skills matter to understand and answer questions asked during the period of the assessment. This may enforce the respective colleges and other concerned governmental organizations to revise the curricula on how the students' language barrier can be reduced.

The FGD sessions showed that participants expressed their ideas on the importance of NCA towards the students' academic efforts to work hard. However, they complained about the representativeness of the assessment tools, assessors and way of assessment that might contribute to their failure to pass the exam. They counted also a lack of training in skill gaps and the institutional model exam at college level, computer-based examination, misconduct of some assessors, lack of preparation among some instructors, and the language barrier as a bottleneck for their poor academic performances. The students hated their profession because they were expected to perform so many activities in their work rather than their major duties. They perceived themselves as a marginalized worker group. This might have policy implications towards the revision of HEP.

This study is limited in its cross-section behavior that could not consider the cause and effect relationship. Due to resource limitation, the study was conducted in one fifth of the colleges and that may lack in representing the exact phenomenon among all RHSCs.

\section{Conclusions}

This study concludes that the proportion of students passing the NCA is below half and low. The students' father's education status and occupation, and the students' English language understanding ability were significantly associated with their academic achievements in the NCA. Therefore, the RHSCs and the respective ministries should give due attention to the inclusion of English language as a unit of competency or changing the media of instruction with the local language; the government and other stakeholders should give priority to paternal awareness towards the benefit of HEP at lower levels. Furthermore, prospective studies at wider settings are recommended for exploring more potential factors related to the students' academic performance in the NCA.

\section{Abbreviations}

ANRS, Amhara National Regional State; CI, confidence interval; DHSC, Dessie Health Science College; FGD, focus group discussion; HEP, health extension program; HESs, health extension students; NCA, national competence assessment; RHSCs: Regional Health Sciences Colleges; SD, standard deviation; TVET, technical and vocational education and training.

\section{Ethical Consideration}

Ethical review was obtained from the Ethical Review Board of the College of Medicine and Health Sciences, Wollo University. Participants under the age of 18 years were approved by the ethical review board to provide informed consent on their own behalf. Permission was obtained from Dessie Health Science College. Informed consent was 
obtained from each study participant prior to data collection. Strict confidentiality of responses was maintained during the study and the data given by the participants was used only for research purposes. This study was conducted in accordance with the Declaration of Helsinki.

\section{Acknowledgments}

The authors thank the Ethical Review Board of the College of Medicine and Health Sciences, Wollo University for the ethical review process. The authors also thank supervisors, data collectors, study subjects and all other individuals for their contributions.

\section{Author Contributions}

All authors made a significant contribution to the work reported, whether that is in the conception, study design, execution, acquisition of data, analysis and interpretation, or in all these areas; took part in drafting, revising or critically reviewing the article; gave final approval of the version to be published; have agreed on the journal to which the article has been submitted; and agree to be accountable for all aspects of the work.

\section{Disclosure}

The authors declare that they have no competing interests.

\section{References}

1. Sachs-Israel M. The SDG 4-education 2030 agenda and its framework for action-the process of its development and first steps in taking it forward. Bildung und Erziehung. 2016;69(3):269-290. doi:10.7788/ bue-2016-0303

2. Ross CE, Mirowsky J. Why education is the key to socioeconomic differentials in health. Handb Med Sociol. 2010;6:33-51.

3. Ali N, Jusof K, Ali S, Mokhtar N, Salamat ASA. The factors influencing students'performance at Universiti Teknologi Mara Kedah, Malaysia. Manag Sci Engg. 2009;3(4):81-90.

4. Africa phone books. Dessie College of Health Science; 2020 [cited July 30, 2020]. Available from: https://africaphonebooks.resolff.com/ ethiopia/en-US/dessie-health-science-college.
5. Africa phone books. Amhara National Regional State Debre Berhan Health Science Collage; 2020 [cited July 30, 2020]. Available from: https://businessguide.ezega.com/Default.aspx?action= BussinessDetail\&pid $=763895 \&$ bid $=1382235 \&$ cid $=773355$.

6. Assefa Y, Gelaw YA, Hill PS, Taye BW, Van Damme W. Community health extension program of Ethiopia, 2003-2018: successes and challenges toward universal coverage for primary healthcare services. Global Health. 2019;15(1):24. doi:10.1186/s12992-019-0470-1

7. Workie NW, Ramana GN The health extension program in Ethiopia. 2013

8. Alebachew A, Waddington C. Improving Health System Efficiency: Ethiopia: Human Resources for Health Reforms. World Health Organization; 2015.

9. Krishnan P, Shaorshadze I. Technical and Vocational Education and Training in Ethiopia. International Growth Centre, London School of Economics and Political Science; 2013.

10. Ministry of Education. National Technical and Vocational Education and Training (TVET) Strategy. 2008.

11. Singh S, Malik S, Singh P. Research paper factors affecting academic performance of students. Indian J Res. 2016;5(4):176-178.

12. Farooq MS, Chaudhry AH, Shafiq M, Berhanu G. Factors affecting students' quality of academic performance: a case of secondary school level. J Qual Technol Manag. 2011;7(2):1-14.

13. Hailu A, Ditta H, Zewdie Z. Competency assessment and factors associated with it among health professionals at Debre Birhan Health Science College. Open J Nurs. 2014;2014.

14. Hijaz ST, Naqvi SR. Factors affecting students' performance: a case of private colleges in Bangladesh. $J$ Sociol. 2006;3(1):44-45.

15. Tiruneh WA, Petros P. Factors affecting female students' academic performance at higher education: the case of Bahir Dar University, Ethiopia. Afr Educ Res J. 2014;2(4):161-166.

16. Ozowuba GU Relationship between English proficiency and academic achievement of Nigerian secondary school students. 2018.

17. Rafiu J, Nwalo KIN. Effect of English language proficiency on students performance in cataloguing and classification courses in polytechnic-based library schools in Nigeria. Int J Lib Inf Sci. 2016;8(6):54-61. doi:10.5897/IJLIS2016.0708

18. Dhaqane MK, Afrah NA. Satisfaction of students and academic performance in Benadir University. J Educ Pract. 2016;7(24):59-63.

19. Martirosyan NM, Hwang E, Wanjohi R. Impact of English proficiency on academic performance of international students. J Int Stud. 2015;5(1):60-71.

20. Kaliyadan F, Thalamkandathil N, Parupalli SR, Amin TT, Balaha MH, Ali WHAB. English language proficiency and academic performance: a study of a medical preparatory year program in Saudi Arabia. Avicenna $J$ Med. 2015;5(4):140. doi:10.4103/22310770.165126

\section{Publish your work in this journal}

Advances in Medical Education and Practice is an international, peerreviewed, open access journal that aims to present and publish research on Medical Education covering medical, dental, nursing and allied health care professional education. The journal covers undergraduate education, postgraduate training and continuing medical education including emerging trends and innovative models linking education, research, and health care services. The manuscript management system is completely online and includes a very quick and fair peer-review system. Visit http://www.dovepress.com/testimonials.php to read real quotes from published authors. 